\title{
Terminal Dan Stasiun Kereta API \\ Sebagai Prasarana Moda Terintegrasi Transportasi Komuter REgional DAN LOKAL BERKONSEP WAYFINDING Di KOTA DEPOK
}

\author{
AstikaAprilliana, MDE Purnomo, Leny Pramesti \\ Program StudiArsitektur \\ Fakultas Teknik \\ Universitas Sebelas Maret, Surakarta \\ Email : astika.aprilliana@hotmail.co.id
}

\begin{abstract}
Bus terminal and railway station's planning and designing in Depok motivated by the government's plan in realizing an integrated transportation in this city. The need of bus terminal and train station's integration is to easily facilitate the movement and displacement modes for the user of transportation mode (commuter) especially in Depok City. Design issues found is that how can the circulatory sistem be able to facilitate the movement and displacement modes for commuters, that are efficient, swift, and safe, also accommodated its building system. The design method used the concept of wayfinding. The application of wayfinding concept is able to resolve the design issues such as the design of circulatory sistem, which are efficient, swift, and safe, also accommodated its building system. In the wayfinding concept, users are the main concern, specifically on the movement and displacement towards a mode. According to the wayfinding concept, the problem solving is that the users make and execute the decision, also know and understand their environment. It influences the design of wayfinding with circulation planning and space layout, also the information design, in order to reach the success of wayfinding design which are efficient, swift, and safe, and accommodated its building system.
\end{abstract}

Keywords: Architecture, Bus Terminal, Circulation, Commuter, Integrated, Layout, Signage Design, Train Station, Transportation, Wayfinding

\section{PENDAHULUAN}

Depok ialah sebuah kota yang terletak di pinggiran ibukota Indonesia, yaitu Jakarta. Sebagian besar penduduk yang bermukim di Depok bekerja di Jakarta. Realita ini berdampak pada jumlah kaum penglaju (komuter) yang terus meningkat (kompas.com). Sebagai bagian dari wilayah Jabodetabek yang penduduknya dinamis, Kota Depok dituntut untuk memiliki sarana transportasi yang mendukung kehidupan jutaan warganya. Sarana transportasi umum bagi komuter di Kota Depok sangat beragam jenisnya, di antaranya metromini, KRL (Kereta Api Listrik), bus kota, dan angkutan kota.

Kota Depok memiliki 1 terminal bus dan 5 stasiun kereta api yang setiap hari digunakan para komuter untuk pergi ke tempat tujuannya. Di tengah kota sendiri terdapat "Terminal Bus Depok dan Stasiun Kereta Api Depok Baru" yang saat ini pemerintah daerah akan mengintegrasikan kedua prasarana moda transportasi tersebut. Selain karena jarak antar lokasi yang berdekatan, integrasi antara terminal bus dan stasiun kereta api ini bertujuan untuk memudahkan komuter untuk berpindah moda.

Rencana pemerintah untuk mengintegrasikan kedua prasarana moda transportasi ini merupakan program pembangunan kota di Kota Depok berdasarkan RTRW Kota Depok tahun 2012-2032. Rencana pengembangan sistem transportasi ini bertujuan untuk meningkatkan pelayanan jaringan transportasi wilayah.

Terminal dan stasiun kereta api yang terintegrasi sebagai objek perencanaan dan perancangan, harus dapat memudahkan pergerakan dan perpindahan komuter. Salah satu solusi untuk dapat memudahkan pergerakan dan perpindahan komuter, serta dapat meminimalkan cross circulation, yaitu dengan menggunakan konsep 
wayfinding. Penerapan konsep wayfinding bertujuan agar para komuter dapat dengan mudah, aman, dan lancar untuk menuju suatu lokasi di dalam bangunan, sehingga dapat terakomodasi dengan baik dalam building sistem-nya.

\section{II.METODE}

Konsep desain wayfinding yang digunakan dalam perencaan, diterapkan pada sistem sirkulasi dan sistem penanda di dalam bangunan. Konsep sistem sirkulasi dengan membedakan area kedatangan dan keberangkatan pada terminal dan stasiun. Tujuannya agar memudahkan komuter dalam pergerakan dan perpindahan moda, sehingga sistem sirkulasi menjadi efisien, lancar, dan aman, serta minimalisasi terjadinya cross circulation dalam bangunan. Penggunaan penanda-penanda yang juga merupakan sarana dari objek rancangan juga dibutuhkan untuk memudahkan komuter dalam berpindah tempat menuju lokasi tertentu di dalam bangunan (Paul Arthur, 1992).

\section{ANALISIS}
A. Analisis Peruangan
1. Pengguna
Pengguna terdiri dari:
a. Penumpang (komuter)
b. Pengantar dan penjemput
c. Pengelola
d. Petugas servis
e. Petugas moda
f. Petugas komersil

2. Analisis Kebutuhan Ruang

Berikut analisis kebutuhan ruang pada terminal dan stasiun integrasi:

a. Area Integrasi

Fungsi area integrasi yaitu mengintegrasikan kedua prasarana moda transportasi, yaitu stasiun kereta api dan terminal bus, agar menjadi terpadu dan memudahkan komuter dalam berpindah moda.

b. Area Terminal

Fungsi area terminal yaitu mewadahi kegiatan pengguna jasa moda transportasi angkot dan bus pada terminal dari kedatangan

keberangkatan.

hingga

c. Area Stasiun

Fungsi area stasiun yaitu mewadahi kegiatan pengguna jasa moda transportasi kereta api Commuter Line Jabodetabek.

d. Mezzanine

Merupakan jalur sirkulasi penghubung antara area integrasi dengan area stasiun.

e. Area Pengelola

Fungsi area pengelola yaitu mewadahi kegiatan pengelola terminal dan stasiun terintegrasi dalam mengawasi jalannya kegiatan.

f. Area Utilitas

Fungsi area utilitas yaitu sebagai area penunjang utilitas area terminal dan stasiun terintegrasi.

g. Area Park and Ride

Fungsi area park and ride yaitu sebagai tempat menitipkan kendaraan komuter, pengelola, dan petugas.

\section{B. Analisis Penataan Tapak}

1. Analisis Tapak

Tujuan:

Menentukan tapak yang digunakan untuk perancangan terminal dan stasiun kereta api terintegrasi.

Kriteria:

a. Berdasarkan RTRW Kota Depok Tahun 2012 - 2032.

b. Berdasarkan rencana tapak oleh Dinas Perhubungan Kota Depok.

c. Dapat dilalui oleh moda transportasi yang akan diintegrasikan.

Hasil:

Tapak yang terpilih berada di Jalan Raya Margonda, Pancoran Mas, Depok. Tapak memiliki luas \pm $35.000 \mathrm{~m}^{2}$ dengan KDB $35-60 \%$.

Batas-batas tapak dapat dilihat pada Gambar 1:

Utara : Pasar Kemiri, Flyover Jalan

Arif Rahman Hakim.

Selatan: ITC Depok, kantor Walikota Depok. 
Barat : Permukiman warga, pertokoan.

Timur: Mall Depok, Saladdin Square, pertokoan, permukiman warga.

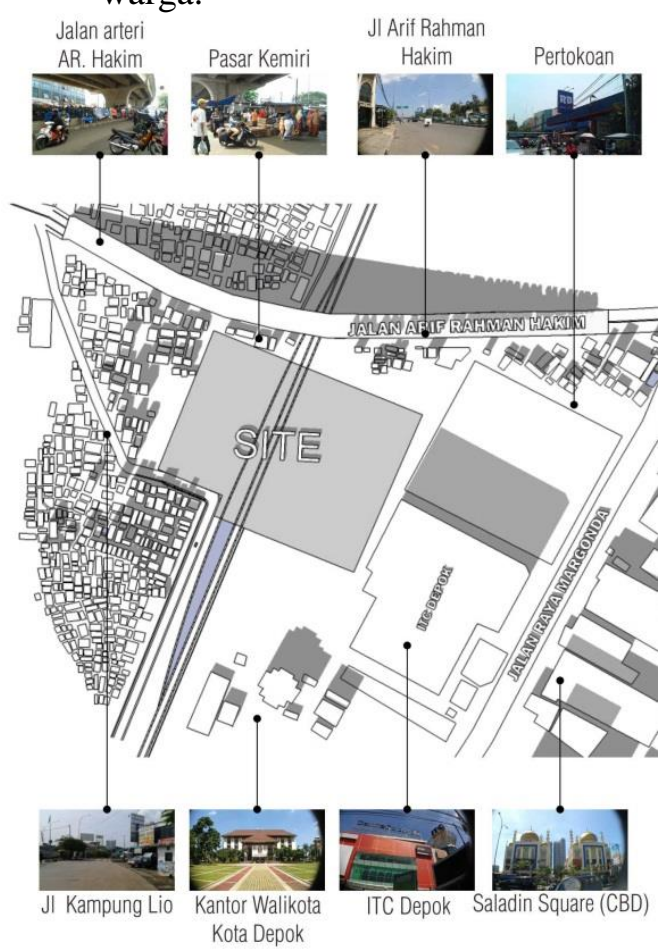

Gambar 1. Tapak dan Batas-batas Tapak.

Potensi tapak:

a. Tapak berada di pusat Kota Depok, yang merupakan area CBD (Central Bussiness District), kantor Walikota Depok, pasar, dan pemukiman warga.

b. Lokasi tapak strategis, berada di jalan protokol Kota Depok dan mudah diakses dari segala arah Kota Depok.

c. Lokasi tapak yang dekat dengan pemukiman warga memudahkan warga dan para komuter dalam aksesnya menuju tapak.

2. Analisis Pola Pencapaian Tujuan:

Menentukan pola pencapaian menuju tapak berdasarkan kriteria-kriteria.

Kriteria:

a. Menyesuaikan jalur rel kereta api yang sudah ada.

b. Kemudahan akses seluruh pengguna. c. Akses moda transportasi nantinya tidak mengganggu lingkungan sekitar.

d. Mengutamakan akses pejalan kaki dengan jarak tempuh tidak lebih dari $800 \mathrm{~m}$ atau setidaknya seorang pejalan kaki membutuhkan waktu lima menit dari jalan menuju terminal dan stasiun terintegrasi.

Hasil:

Main Entrance (ME) berada pada timur bangunan, digunakan untuk akses masuk bus, angkot, kendaraan pribadi, serta pejalan kaki dari Jalan Raya Margonda.

Side Entrance (SE) berada pada barat bangunan, digunakan untuk akses masuk kendaraan pribadi dan pejalan kaki, dari Jalan Kampung Lio (Lihat Gambar 2).

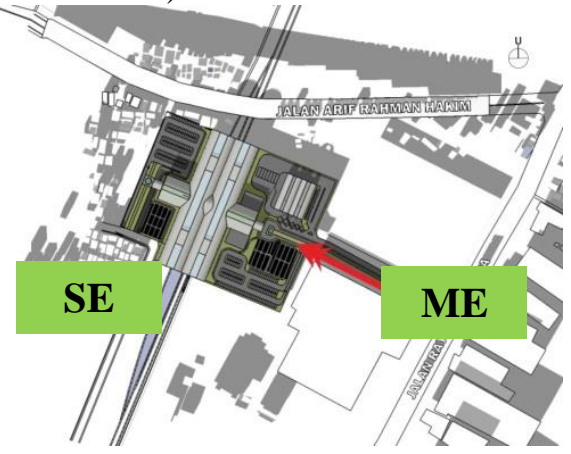

Gambar 2. Pola Pencapaian.

3. Analisis Pemintakatan

Tujuan:

Menentukan konsep pemintakatan akhir pada bangunan terminal dan stasiun terintegrasi.

Kriteria:

a. Kemudahan akses seluruh pengguna.

b. Berdasarkan analisis-analisis yang telah dibahas pada poin sebelumnya.

Hasil:

Berikut konsep pemintakatan akhir pada bangunan terminal dan stasiun integrasi yang direncanakan (Lihat Gambar 3):

a. Bangunan utama yang berupa terminal dan stasiun terintegrasi ditempatkan di atas rel kereta api eksisting. Untuk bangunan stasiun 
berada di atas rel, namun untuk bangunan terminal akan diletakkan pada bagian timur stasiun karena letak arus pencapaian menuju tapak juga berada di timur stasiun. Hal ini ditujukan untuk memudahkan akses pengguna.

b. Zona park and ride pada stasiun, diletakkan pada dua tempat yang terpisah, yaitu pada bagian barat bangunan dan timur bangunan. Hal ini untuk memudahkan pencapaian penumpang yang berasal dari arah timur (Jalan Kampung Lio), maupun barat tapak (Jalan Raya Margonda).

c. Zona pengelola dan utilitas diletakkan pada bagian utara dikarenakan optimalisasi bagian bangunan utama agar terkena angin segar serta matahari pagi dan siang.

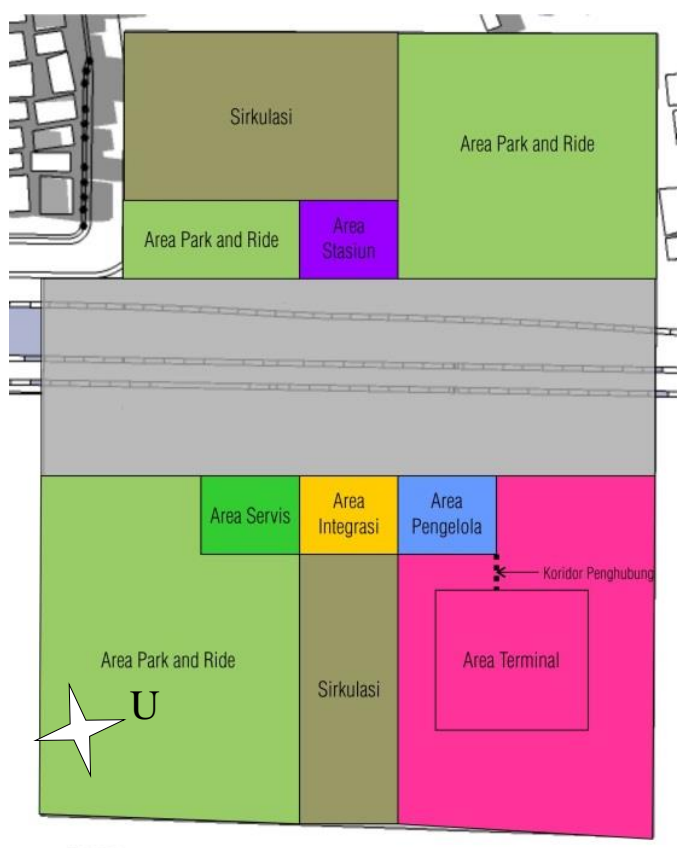

Gambar 3. Pemintakatan Akhir pada Bangunan.

C. Analisis Bentuk danTatanan

1. Analisis Massa Bangunan Tujuan:

Menentukan gubahan massa bangunan sebagai dasar perancangan terminal dan stasiun terintegrasi.

Kriteria: a. Penempatan massa sesuai dengan KDB setempat, yaitu 35-60\%.

b. Penempatan massa menyesuaikan letak rel eksisting.

Hasil:

Dari kriteria tersebut, maka didapat massa bangunan seperti Gambar 4.

Area integrasi merupakan titik kumpul pertama dari keseluruhan bangunan, sehingga penempatan main entrance berada pada area ini.

Area terminal terletak dekat dengan area integrasi dengan dihubungkan oleh koridor penghubung untuk memudahkan dan menjaga keselamatan pengguna dari benda bergerak seperti kendaraan umum bus dan angkot.

Area stasiun terletak berseberangan dengan area integrasi yang dihubungkan oleh mezzanine sebagai penghubung berada atas jalur kereta.

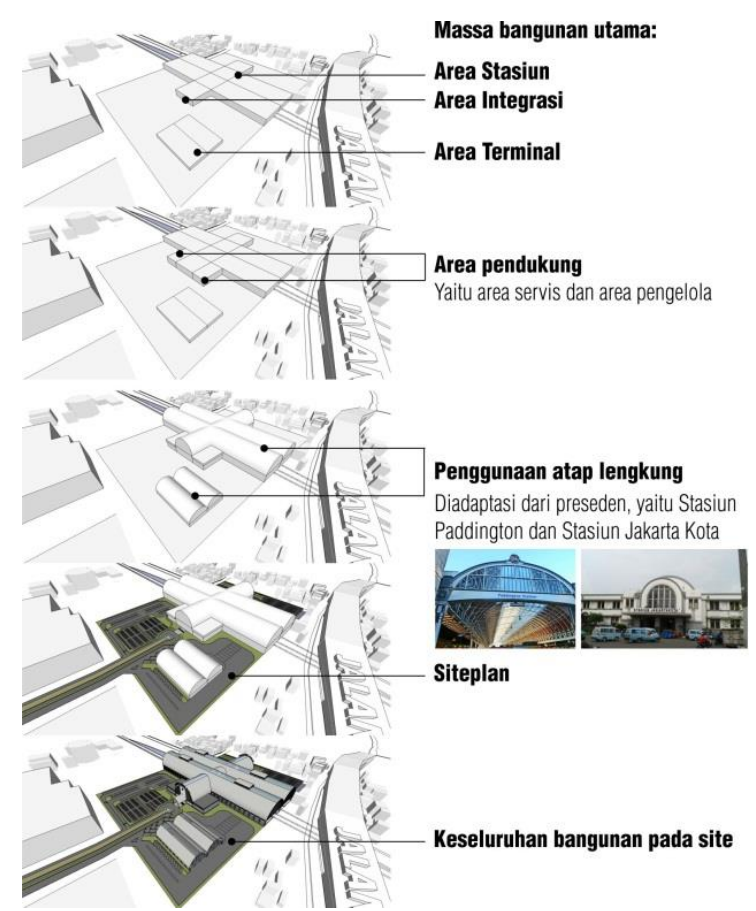

Gambar 4. Gubahan Massa Bangunan.

2. Analisis Bentuk Bangunan

Tujuan:

Menentukan bentuk bangunan yang digunakan sebagai dasar perancangan terminal dan stasiun terintegrasi. 
Kriteria:

a. Bentuk bangunan mampu mewadahi fungsi ruang.

b. Bentuk bangunan dari struktur bentangan lebar, cenderung berbentuk lengkung yang menyerupai bentuk lama Stasiun Depok Baru.

Hasil:

Bentuk bangunan yang dihasilkan berbentuk simetris dengan bentangan yang lebar. Bentuk bangunan berasal dari preseden, yaitu Stasiun Jakarta Kota dan Stasiun Paddington, London. Bentuk bangunan ini cenderung simetris dan diadaptasi oleh bentuk struktur di dalamnya.

Bentuk bangunan yang diadaptasi oleh gaya Arsitektur Belanda, mampu bertahan hingga 20 tahun kedepan. Bentuk lengkung juga mampu menahan struktur lengkung bentang lebar dengan bentangan 30 meter pada stasiun dan 18 meter pada terminal (Lihat Gambar 5).

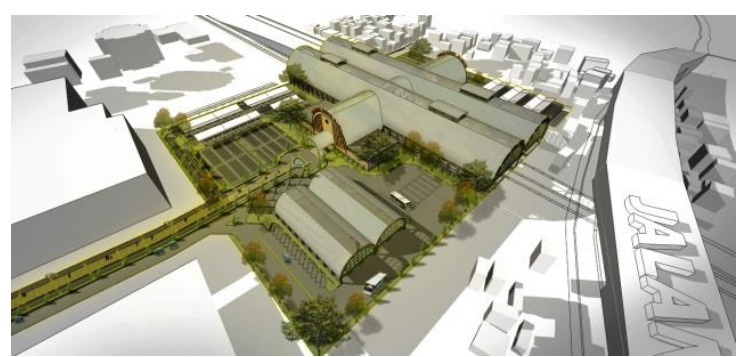

Gambar 5. Bentuk Lengkung pada Desain.

D. Analisis Penerapan Konsep Wayfinding

1. Analisis Sirkulasi

Tujuan:

Menentukan sistem sirkulasi dalam bangunan dengan konsep wayfinding sebagai dasar perancangan terminal dan stasiun terintegrasi (Paul Arthur, 1992).

Kriteria:

a. Menggunakan sirkulasi yang mengutamakan pengguna khususnya komuter.

b. Meminimalkan terjadinya cross circulation. c. Memudahkan seluruh pengguna dalam mencapai suatu tempat.

d. Tidak membutuhkan waktu yang lama untuk menuju suatu tempat.

e. Sirkulasi dapat digunakan oleh pengguna difabel.

Sirkulasi pada perencanaan terdiri dari:

a. Sirkulasi Luar Bangunan

Berikut konsep skematik sirkulasi luar bangunan pada Gambar 6.

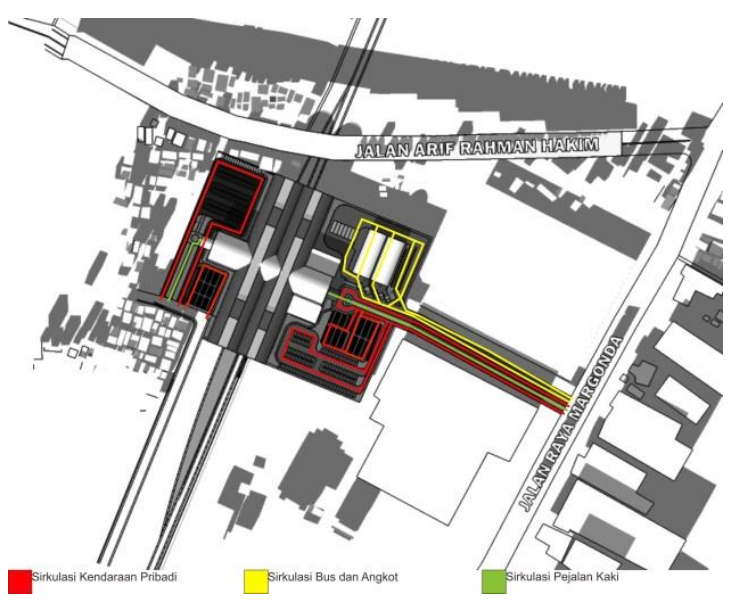

Gambar 6. Sirkulasi Luar Bangunan Terminal dan Stasiun yang Direncanakan.

Sirkulasi luar bangunan dibedakan berdasarkan pengguna dan moda yang digunakan:

1) Sirkulasi pejalan kaki dari arah Jalan Margonda menggunakan pencapaian langsung menuju bangunan.

2) Sirkulasi pengguna berkendara masuk menuju taman parkir melewati pos jaga masuk, parkir, kemudian memutar menuju arah datang melalui pintu keluar.

3) Sirkulasi kendaraan bus dan angkot ketika masuk ke tapak, langsung menuju ke area kedatangan untuk menurunkan penumpang dan bergerak ke arah keberangkatan untuk menjemput penumpang. 
4) Sirkulasi kereta api dibagi menjadi sirkulasi ke arah Bogor dan ke arah Jakarta.

b. Sirkulasi Dalam Bangunan

1) Sirkulasi Horizontal Sirkulasi horizontal dalam bangunan bersifat terpola, dengan mengarahkan pengguna langsung menuju tempat tujuan. Meskipun terpola, sirkulasi ini tidak kaku, dengan menambahkan dinamika ruang, seperti retail, warna-warna, dan iklan komersil (Lihat Gambar 7,8, dan 9).

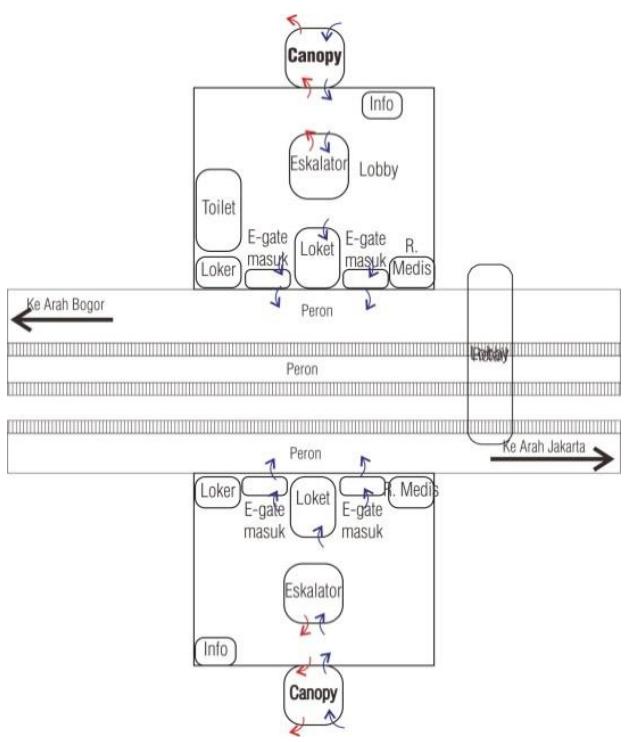

Gambar 7. Sirkulasi Horizontal Lantai 1.

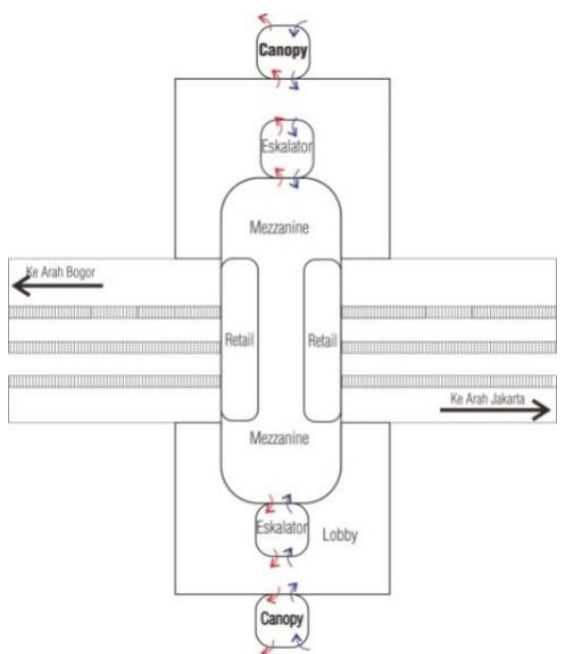

Gambar 8. Sirkulasi Horizontal Mezzanine.
Bangunan terminal dan stasiun terintegrasi ini terdiri dari 3 lantai, yaitu lantai satu, lantai mezzanine, dan lantai basement. Lantai mezzanine digunakan untuk perpindahan jurusan kereta api Commuter Line dan juga untuk perpindahan moda melalui basement. Lantai basement digunakan untuk penumpang turun dari kereta, serta perpindahan moda menuju terminal melalui koridor penghubung pada basement.

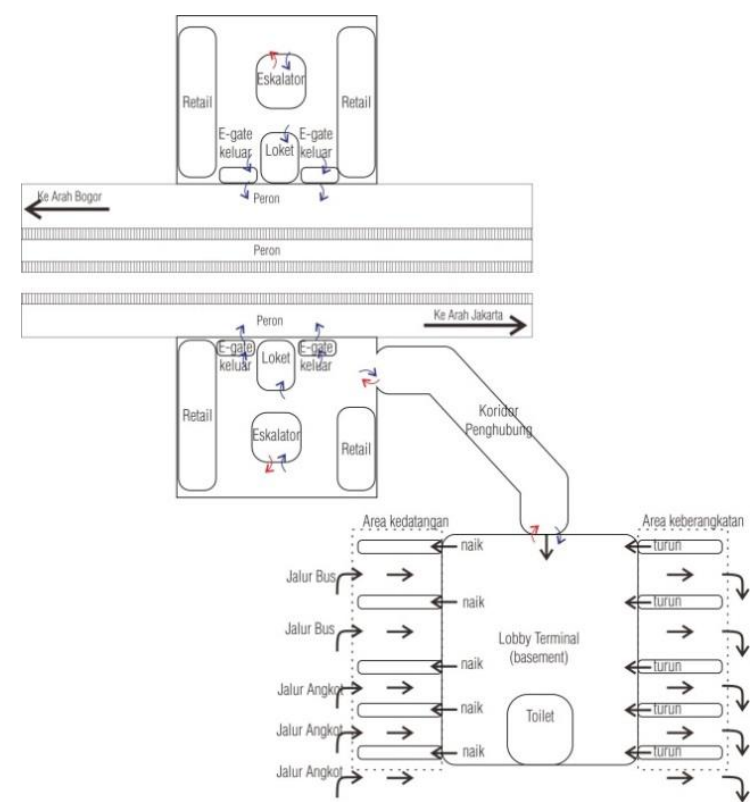

Gambar 9. Sirkulasi Horizontal Basement.

2) Sirkulasi Vertikal

a) Ramp

Ramp pada bangunan terminal dan stasiun terintegrasi ini terdapat pada pencapaian menuju canopy dan lobby baik pada area terintegrasi dan pada area stasiun.

b) Tangga dan eskalator Tangga digunakan untuk penunjang sirkulasi vertikal bagi para komuter yang diletakkan di peron sebagai alat transportasi vertikal 
komuter yang turun dari kereta. Eskalator digunakan oleh seluruh pengguna, dan diletakkan di tengah lobby sebagai pencapaian menuju mezzanine dan basement.

\section{c. Sirkulasi Menuju Moda}

Pintu masuk kereta dibedakan untuk pintu kedatangan dan keberangkatannya. Untuk pintu kedatangan, menggunakan 2 pintu belakang tiap gerbong. sedangkan untuk pintu keberangkatan, menggunakan 2 pintu depan tiap gerbong. Sirkulasi komuter menuju moda pada stasiun dari arah lobby menuju gerbang electronic gate masuk, kemudian masuk kedalam peron, dan langsung menuju ke dalam kereta (Lihat Gambar 10-13).

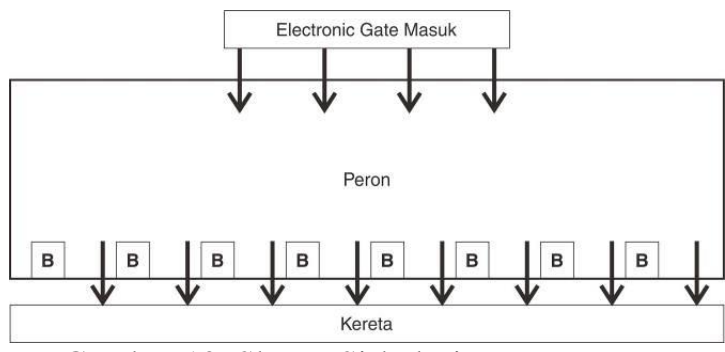

Gambar 10. Skema Sirkulasi Komuter yang Berangkat.

Sedangkan komuter yang turun (datang), diarahkan menuju basement agar tidak terjadi sirkulasi silang terhadap komuter yang berangkat (menggunakan 2 pintu belakang tiap gerbong).

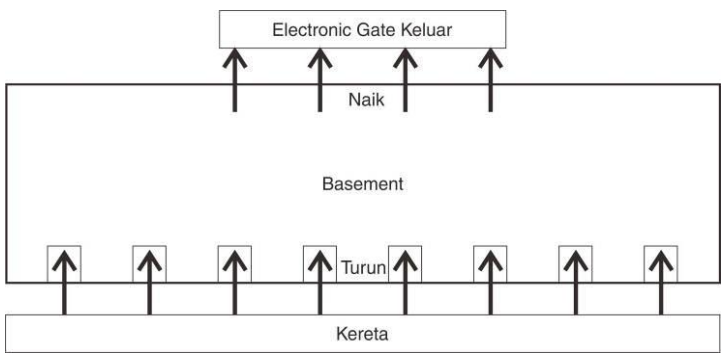

Gambar 11. Skema Sirkulasi Komuter yang Datang.
Secara singkat, skema sirkulasi pada peron, sebagai berikut.

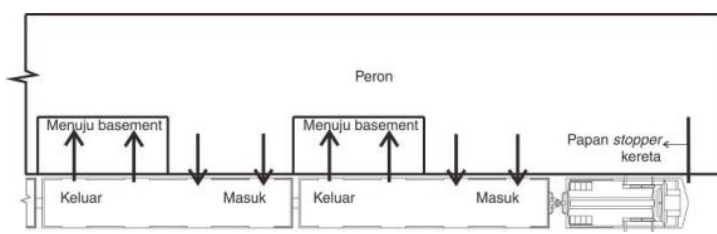

Gambar 12. Skema Sirkulasi Komuter yang

Datang dan Berangkat.

Pada terminal, untuk memudahkan komuter menaiki bus atau angkot serta tidak menghambat arus sirkulasi moda, maka dibedakan menjadi area kedatangan dan keberangkatan. Komuter dari area integrasi untuk menuju area terminal diarahkan turun menuju basement pada area integrasi dan berjalan menuju koridor penghubung untuk menuju lobby terminal dengan menggunakan sistem sirkulasi vertikal (eskalator) kemudian menuju peron yang sesuai dengan lajur bus dan angkot yang dituju.

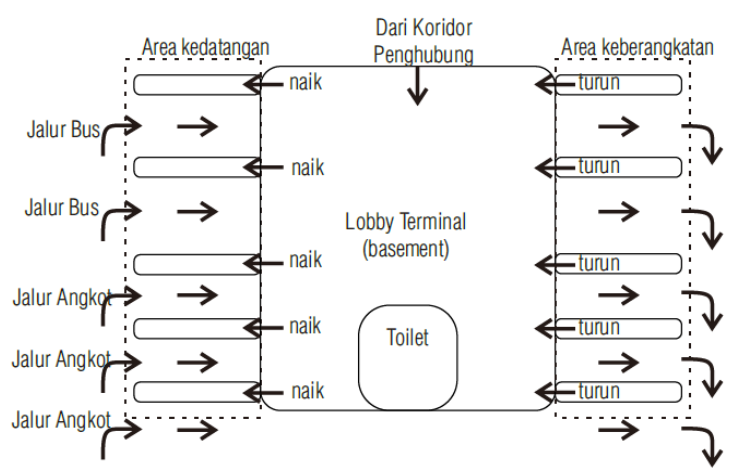

Gambar 13. Skema Sirkulasi Keberangkatan dan Kedatangan pada Terminal.

2. Analisis Pengaturan Informasi Grafis

Tujuan:

Menentukan sistem penanda (signage) dalam bangunan sebagai penunjang konsep wayfinding bangunan terminal dan stasiun terintegrasi.

Kriteria: 
a. Menghindari terjadinya masalah pada pengguna khususnya komuter, seperti ambiguitas, konflik, silau, dan gangguan lainnya.

b. Digunakan untuk orientasi pengguna dalam menentukan arah.

c. Penanda mudah dilihat dan mudah dibaca oleh pengguna.

Hasil:

Jenis informasi grafis yang digunakan adalah:

\section{a. Tipograf}

Merupakan penanda (signage) yang berisi tulisan-tulisan dan panah petunjuk arah. Penempatan penanda ini diletakkan pada lokasi yang berpotensi terjadinya masalah bagi komuter. Bentuk huruf dan ukuran huruf harus mudah dibaca. Huruf yang digunakan adalah Helvetica dengan rasio lebar 1:5 dan tinggi 1:8 (Lihat Gambar 14).

\section{Stasiun}

\section{Depok Baru}

$$
\begin{aligned}
& \vec{\leftarrow} \quad \text { i Informasi / Information } \\
& \rightarrow \text { \& Keamanan / Security } \\
& \rightarrow \text { Terminal / Bus Station } \\
& \boldsymbol{\Gamma} \\
& \text { K } 1 \text { Musholla / Prayer Room } \\
& \mathbf{K} \text { Ruang Menyusui / Nursery Room } \\
& \mathbf{K} \text { ATM / ATM } \\
& \text { K } \text { Loker / Locker } \\
& \text { Gambar 14. Tipograf yang } \\
& \text { Digunakan pada Perancangan. }
\end{aligned}
$$

\section{b. Piktograf}

Merupakan penanda (signage) berupa gambar yang menunjukan karakter suatu tempat (Lihat Gambar 15).

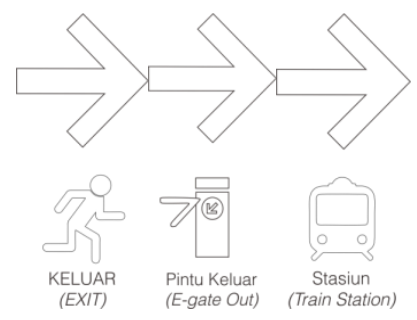

Gambar 15. Piktograf yang

Digunakan pada Perancangan.

\section{c. Kartograf}

Merupakan petunjuk berupa peta yang menunjukkan ruangruang di dalam bangunan terminal dan stasiun terintegrasi serta menunjukkan keberadaan stasiun dengan stasiun-stasiun lainnya dalam lingkup Jabodetabek (Lihat Gambar 16).

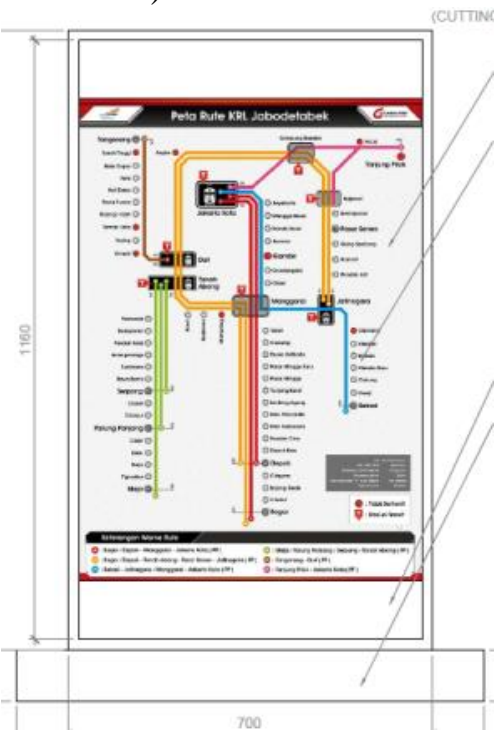

Gambar 16. Kartograf yang Digunakan pada Perancangan.

\section{Analisis Elemen Pembentuk}

Ruang

Tujuan:

Menentukan elemen pembentuk tiap ruang pada terminal dan stasiun terintegrasi yang direncanakan.

Kriteria:

a. Kebutuhan tiap-tiap ruang berdasarkan fasilitas, penutup lantai, dinding, dan atap ruangan.

b. Signage atau penanda yang digunakan.

c. Berdasarkan beberapa hasil analisis yang telah diputuskan pada poin sebelumnya, yaitu analisis material dan finishing, interior bangunan, sistem penghawaan dan pencahayaan, serta pengaturan grafis. 


\begin{abstract}
d. Terdapat fasilitas untuk penyandang cacat.

Hasil:

Elemen pembentuk ruang ini terdiri dari signage yang digunakan pada masing-masing ruang; material dan finishing plafon, dinding, dan lantai; fasilitas ruang; serta jenis pencahayaan dan penghawaan yang digunakan pada masing-masing ruang.
\end{abstract}

\section{KESIMPULAN (KONSEP DESAIN)}

Konsep perencanaan dan perancangan terminal bus dan stasiun kereta api ini mengacu kepada desain wayfinding, khususnya diterapkan pada sistem sirkulasi. Sistem sirkulasi dirancang terpola namun tetap tidak kaku dengan penambahan dinamika ruang, seperti adanya kegiatan pada retail khususnya pada koridor penghubung, penambahan warna-warna pada signage, serta papan iklan komersil. Selain itu, dengan membedakan sistem sirkulasi keberangkatan dan kedatangan pada perancangan terminal bus dan stasiun kereta api ini, maka permasalahan sirkulasi silang dapat dipecahkan, sehingga sistem sirkulasi dalam bangunan menjadi efisien, lancar, dan aman serta dapat terakomodasi dalam building sistem-nya.

Dari hasil analisa serta hasil korelasi dari beberapa data di atas, maka diperoleh hasil berupa rancangan terminal bus dan stasiun kereta api sebagai berikut.

Nama Objek : Stasiun Integrasi Depok

Lokasi

Luas Lahan

: Jl. Raya Margonda

Luas Bangunan

: $35.000 \mathrm{~m}^{2}$

Daya Tampung

Kegiatan

$: 31.707 \mathrm{~m}^{2}$

: 1.839 orang

: Turun naik

penumpang

dari/menuju suatu

moda

Gambar hasil rancangan terminal dan stasiun kereta api yang direncanakan dapat dilihat pada Gambar $17-21$.

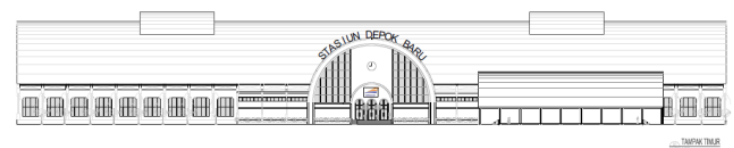

Gambar 17. Tampak Timur.

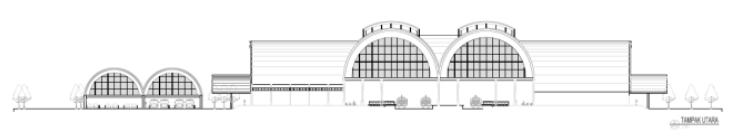

Gambar 18. Tampak Utara.
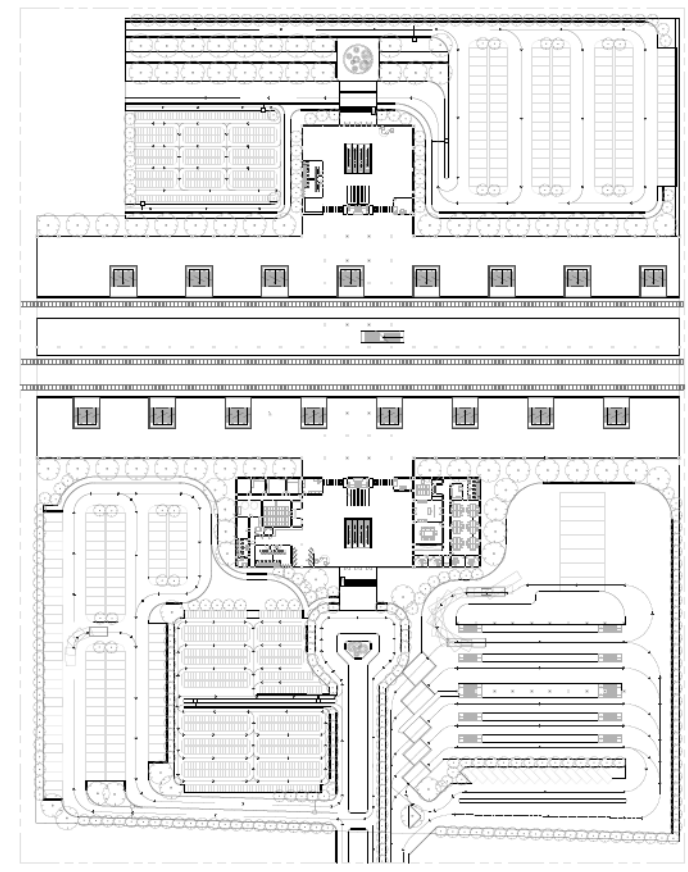

Gambar 19. Tata Tapak.

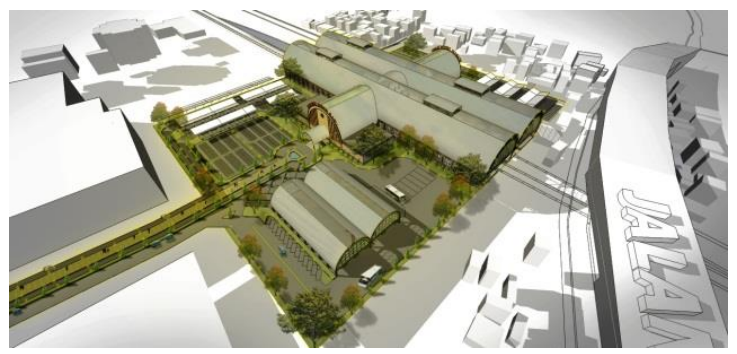

Gambar 20. Perspektif.

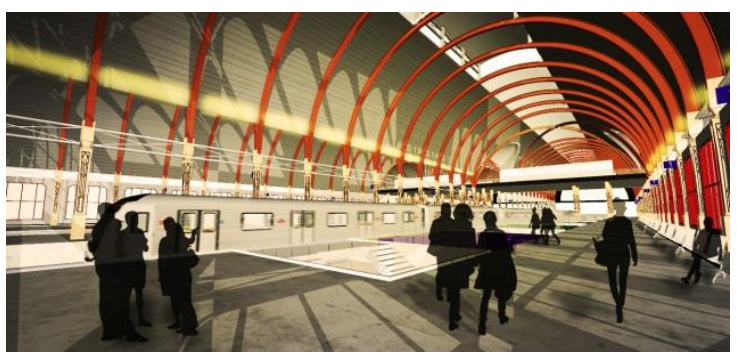

Gambar 21. Perspektif Interior Peron. 


\section{REFERENSI}

RTRW Kota Depok Tahun 2012 - 2032.

hhArthur, Paul and Romedi Passini. 1992.

Wayfinding, People, Signs, and

Architecture. Canada: McGraw-Hill

Ryeson Limited.

www.kompas.com 